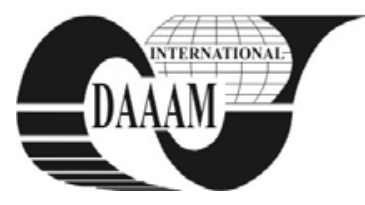

\title{
NUMERICAL SIMULATION OF THE CONVECTIVE DRYING OF APPLE SLICES
}

\author{
HUGENSCHMIDT, S[tephan] \& HOFACKER, W[erner] C[hristian]
}

\begin{abstract}
The quality of dried products mainly depends on temperature and moisture content changes during the drying process, as they govern the quality determining reactions taking place during the dehydration. For optimizing the quality of the drying process it is valuable to predict moisture content and temperature of the drying material during the drying process. Heat and mass transport in the material and on its surface can be described by partial differential equations. This paper describes a mathematical technique originally used in aerospace engineering which allows for solving the partial differential equations numerically. The lumped parameter model of the drying material enables to predict the influence of external process parameters on the drying characteristics of the product and its temperature.

Key words: partial differential equations, lumped parameter model, simulation, convective drying, heat and mass transfer
\end{abstract}

\section{INTRODUCTION}

Biological products can be preserved by dewatering, as deterioration reactions caused by microorganisms are stopped at low moisture content. It is common to dry agricultural products by hot air forced convection which is a very energy intensive process that consumes up to $25 \%$ of national industrial energy in the developed countries (Mujumdar, 1999). Due to economic and environmental reasons it is aimed to minimize energy demand. As the quality of a drying process also depends on drying time and product quality, optimization has to account for all three aspects (Sturm, 2010). Simulations of coupled heat and mass transfer within the product are instruments for designing drying equipment (Giericke \& Kind, 2009). They facilitate the prediction of the most convenient drying conditions if the dependency of the product's drying behavior on process conditions is known. Convective drying is a complex process involving simultaneous, coupled heat and mass transfer within the drying material and at the boundary to the drying air. Extensive research has been directed towards mathematical prediction of the drying process of biological materials, but no universally applicable model has been formulated yet (McMinn and Magee, 1999). Most of the approaches presented in literature provide simplifying assumptions such as negligible shrinkage or constant thermophysical properties. There is no published mathematical model of the drying process of foodstuffs differentiating between mass transfer in liquid and gaseous state. In the present work a lumped parameter model of the drying material was established taking into account temperature and moisture dependent material and transport properties, shrinkage and mass transfer occurring in liquid and gaseous state.

\section{MATHEMATIC MODEL}

Coupled partial differential equations describing simultaneous heat and mass transport within the drying material are solved by discretizing apple slices in nodes, representing the finite elements of the problem area (Fig. 1). Nodes of height $s$ and exchange area $A$ are treated as isothermal and as of uniform moisture content. The governing partial differential equations are transformed into a system of non-linear equations solved by using an implicit forward backward differencing method. Heat flow and mass streams in liquid and gaseous state $\left(\dot{H}_{j}, \dot{M}_{w j}\right.$, $\dot{M}_{w j}$ ) between node $j$ and $j+1$ are calculated by analogue mathematical approaches.

$$
\begin{gathered}
\dot{H}_{j}=\lambda_{j} \cdot \frac{A}{s} \cdot\left(\vartheta_{j}-\vartheta_{j+1}\right) \\
\dot{M}_{w j}=\kappa_{j} \cdot \rho_{j} \cdot \frac{A}{s} \cdot\left(X_{j}-X_{j+1}\right) \\
\dot{M}_{v j}=\mu_{j} \cdot \delta_{j} \cdot \frac{A}{s \cdot R_{v} \cdot T_{j}} \cdot\left(P_{v j}-P_{v j+1}\right)
\end{gathered}
$$

The constants of proportionality (thermal conductivity $\lambda_{j}$, liquid diffusivity $\kappa_{j}$, vapour diffusivity $\mu_{j} \cdot \delta_{j}$ ) are assumed to be functions of local moisture content $X_{j}$ and temperature $\vartheta_{j} . \rho_{j}$ is the density of the drying material, $R_{v}$ the individual gas constant for water vapor, $T_{j}$ is the absolute temperature and $P_{v j}$ the water vapor partial pressure of node $j$. Due to heat of vaporization of water and sorption $\left(h_{v a p}, h_{\text {sorp }}\right)$ the difference in vapor streams entering and leaving the node $\left(\Delta \dot{M}_{v j}=\right.$ $\dot{M}_{v j-1}-\dot{M}_{v j}$ ) leads to a loss of heat within the node $H I_{j}$ :

$$
H I_{j}=\left(\dot{M}_{v j-1}-\dot{M}_{v j}\right) \cdot\left(h_{v a p}-h_{\text {sorp }}\right)
$$

The convective boundary conditions for heat transfer $\left(\dot{H}_{S}\right)$ and vapor stream $\left(\dot{M}_{v s}\right)$ leaving the drying material at the surface (index $s$ ) are given by:

$$
\begin{gathered}
\dot{H}_{s}=\alpha \cdot A \cdot\left(\vartheta_{s}-\vartheta_{a}\right) \\
\dot{M}_{v s}=\beta \cdot \frac{P^{\circ}}{P_{v s}-P_{v a}} \cdot \ln \left(\frac{P^{\circ}-P_{v a}}{P^{\circ}-P_{v s}}\right) \cdot \frac{A}{R_{v} \cdot T_{S}} \cdot\left(P_{v s}-P_{v a}\right)
\end{gathered}
$$

Heat and mass transfer coefficients $(\alpha, \beta)$ are expressed non-dimensional via Nusselt- and Sherwood-number $(\mathrm{Nu}, \mathrm{Sh})$. Depending on flow conditions they can be calculated by different empirical equations. $P^{\circ}, P_{v a}$ and $\vartheta_{a}$ are pressure, water vapor partial pressure and temperature of the drying air.

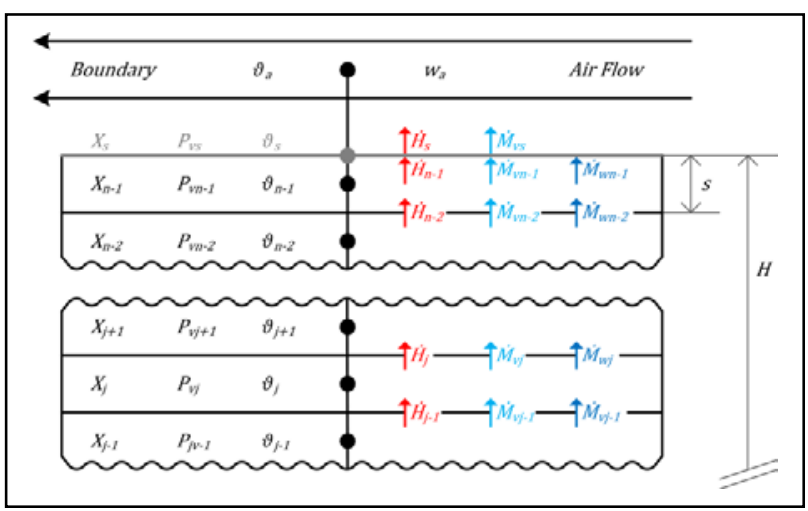

Fig. 1. Sectional view through the drying material 


\section{RESULTS AND DISCUSSION}

Fig. 2 shows the predicted and experimentally determined drying curves for different air temperatures $\left(35^{\circ} \mathrm{C}, 60^{\circ} \mathrm{C}\right.$ and $85^{\circ} \mathrm{C}$ ), whereas velocity and humidity of drying air were held constant. As reported by Sturm (2010) air temperature has the most significant influence on drying time. Drying time can be shortened considerably by increasing air temperature due to the higher temperature difference between the drying surface and air leading to a higher amount of heat being transferred to the drying material. Increasing product temperature also leads to higher water vapor pressures within the product and consequently convective mass transfer increases.

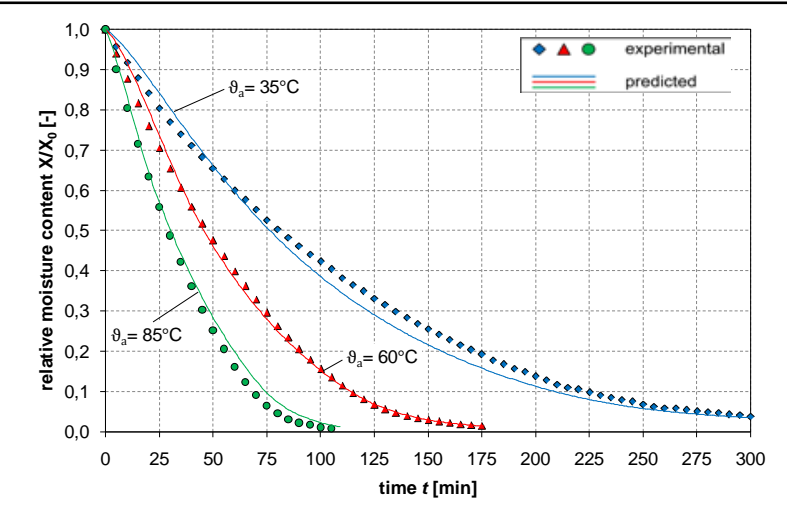

Fig. 2. Predicted and experimentally determined drying curves for different air temperatures $\vartheta_{a}$

Fig. 3 depicts predicted and experimental drying curves at different air velocities $(2.0 \mathrm{~m} / \mathrm{s}, 3.4 \mathrm{~m} / \mathrm{s}$ and $4.8 \mathrm{~m} / \mathrm{s})$ but constant temperature and humidity. Qualitatively the influence of air velocity on drying behavior is similar to that of temperature. Increasing air velocity reduces drying time significantly. This effect decreases with higher velocities. Air velocity influences transfer coefficients at the drying surface. For calculating $\mathrm{Nu}$ and Sh respectively Reynolds-number Re is used being proportional to air velocity. Again predicted data shows a high degree of accuracy. Therefore it can be assumed, that the model reproduces the physical effects correctly.

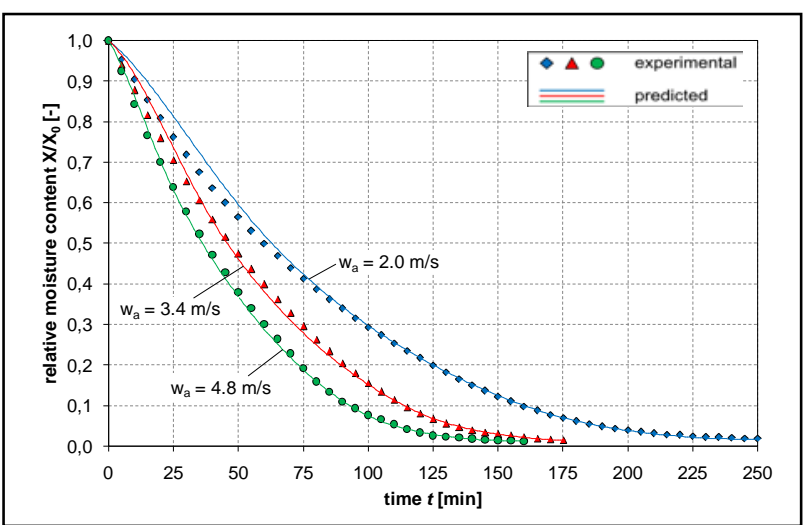

Fig. 3. Predicted and experimentally determined drying curves for different air velocities $w_{a}$

Predicted and experimental measured upper surface temperature of food as function of relative moisture content $X / X_{0}$ is illustrated in Fig. 4. Air properties were constant and equal to $60^{\circ} \mathrm{C}, 3.4 \mathrm{~m} / \mathrm{s}$ and $17.5^{\circ} \mathrm{C}$ for temperature, velocity and dew point temperature respectively. At the beginning of the drying process surface temperature rapidly increases to wet bulb temperature $\approx \beta 0^{\circ} \mathrm{C}$ ). After this warm -up stage temperature increase is significantly reduced due to the cooling effect caused by evaporation at the surface. When moisture content falls below approximately $10 \%$ of the initial content, temperature rises again and approaches that of air temperature.

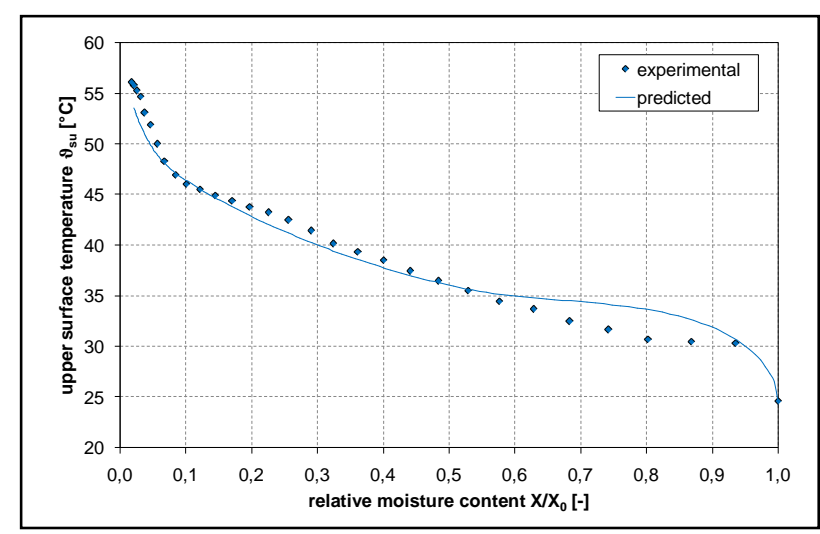

Fig. 4. Predicted and experimentally measured surface temperature $\vartheta_{s}$

According to Pavón-Melendez et al. (2002) predicted temperature differences between the drying surface and interior are marginal as Biot-number is $<1$ during the whole drying process. The heat is transferred rapidly into the interior as the apple slices are quite thin (initially $4 \mathrm{~mm}$ ). Due to shrinkage the thickness is even reduced to nearly one third during drying.

\section{CONCLUSIONS}

The present work introduces a lumped parameter model describing coupled heat and mass transfer phenomena. The main innovation of this study was to differentiate between mass transfer in liquid and gaseous state. Shrinkage and dependency of thermo physical properties on temperature and moisture content respectively was taken into account as well. The mathematical model enables the prediction of moisture content as a function of time within the examined range of process parameters with high accuracy. It was shown that the influences of external drying parameters are predicted correctly. It also enables the prediction of the product surface temperature which is important for taking into account product quality. Further investigation is necessary as the present model neglects three dimensional transport phenomena and local heat and mass transfer coefficients. Due to ambiguous transfer conditions at the lower surface of the apple slices, further experimental data excluding these uncertainties should be generated. Then a second verification of the model with this data could be done.

\section{REFERENCES}

Mujumdar, A. S. (1999). International Drying Symposium Series (IDS): A personal perspective. Drying Technology, Vol. 17, No. 1\&2, pp. xi-xx

Pavón-Melendez, G. Hernández, J. A., Salgado M. A. \& García, M. A. (2002). Dimensionless analysis of the simultaneous heat and mass transfer in food drying. Journal of Food Engineering, Vol. 51, No. 4, pp. 347-353

Sturm, B. (2010). Einfluss der Führung des Trocknungsprozesses auf den Trocknungsverlauf und die Produkteigenschaften empfindlicher biologischer Güter. Fortschrittsberichte Agrartechnik VDI-MEG 491, ISBN 0931-6264, Dissertation Universität Kassel

McMinn, W. A. M. \& Magee, T. R. A (1999). Principles, methods and applications of the convective drying of foodstuffs, Trans IChemE, Vol 77, Part C, pp. 175-193

Giericke, L. \& Kind, M. (2009). Zusammenhang zwischen Trocknungsverlauf und Gutsdicke bei wasserfeuchten, plattenförmigen Gütern. Teil 1: Trocknungsexperimente und Modellierung der Trocknungskinetik, Chemie Ingenieur Technik, Vol. 82, No. 3, pp 327-334 